\title{
Investigation on the Electromagnetic Shielding Performance of Copper Plate and Copper Composite Fabrics: A Comparative Study
}

\author{
İlkan Özkan \\ Çukurova University / Textile Engineering Department / Balcalı Campus, 01330, Sarıçam/ Adana
}

Corresponding Author: İlkan Özkan, iozkan@cu.edu.tr

\begin{abstract}
Recently, the advantages of protective textile materials such as cost-effectiveness, flexibility, lightweight, etc. over metal plates are emphasized in many studies. However, these studies did not provide a comparison of protective performances between fabrics and metal plates. In this study, electromagnetic shielding performances of copper plate and metal composite woven/knitted fabrics were compared. For this purpose, electromagnetic shielding effectiveness of single and double layer copper plate and metal composite fabrics were measured in vertical and horizontal directions. As a result, the copper plate showed better performance than composite fabric samples for both measurement directions. In general, the EMSE of the composite fabrics were lower than $10 \mathrm{~dB}$ for horizontal directions. Only the copper plates provided electromagnetic shielding at a significant level (up to $60 \mathrm{~dB}$ ) against horizontally polarized waves. EMSE behavior of copper plate was similar for both directions due to the isotropic structure and this performance maintained at higher frequency level. On the other hand, gaps in the structure of composite fabrics caused a decrease in EMSE performance against increasing frequency.
\end{abstract}

ARTICLE HISTORY

\author{
Received: 25.10 .2019 \\ Accepted: 12.06.2020
}

\section{KEYWORDS}

Composite fabric, copper plate, electromagnetic shielding, knitted fabric, woven fabric

\section{INTRODUCTION}

Nowadays, various electrical and electronical devices are being used in daily life with developing technology. There are also concerns about the effects of electromagnetic waves emitted from these devices on human health. Therefore, electromagnetic shielding materials are the subject of many kinds of research. Shielding is the main approach to protection against the electromagnetic waves. In conventional approaches, metallic materials are preferred because of their well electromagnetic shielding ability. Whereas the traditional textile products are transparent in the electromagnetic field due to their nonconductive structure. Electromagnetic protective textile materials are easy to produce, flexible, and costeffective when compared to metal plates [1-3]. In addition to these advantages, if these textile structures could show similar or better EMSE performance than metal plates, they may be replaced the metal plates.

There are various studies about the EMSE of textile structures. These researches can be classified as woven, knitted, and nonwoven surfaces in terms of protective surface types. Studies on weaving and knitting generally examine the effects of weave type, number of layers, metal type, and metal density in structure [4-11]. Previous researches show that the increase in metal density and the number of layers increases the EMSE of textile structure [2, $5,9,12-15]$. Some studies stated that the orientation of conductive yarns is effective on EMSE. It was noted that the weft-knitted fabrics have EMSE ability in their course direction [11, 16, 17]. Also, metal composite woven structures provide EMSE only in the direction that including the metal component, and both the weft and warp yarns must contain a conductive component for providing multi-axial shielding [18].

This study aims to compare EMSE characteristics of copper composite woven and knitted fabrics with a copper plate having $50 \mu$ thickness. For this purpose, knitted and woven fabrics were produced by using composite yarn including $50 \mu$ copper wire. EMSE, absorption, and reflection properties of the composite fabric samples and copper plate measured and compared each other. Obtained data were analyzed statistically. The differences between electromagnetic shielding performances of metal plate and composite fabrics

To cite this article: Özkan İ. 2020. Investigation on the electromagnetic shielding performance of copper plate and copper composite fabrics: A comparative study. Tekstil ve Konfeksiyon, 30(2), 156-162. 
were examined and possible reasons for the difference were discussed.

Most of the studies in the literature mentioned the advantages of electromagnetic protective textiles in comparison with metal plates. However, they did not provide information about the performance of electromagnetic protective fabrics in reference to metal plates. The novelties of the research can be listed as follow; the copper plates having the same thickness with the copper wire in fabric structures were used for objective comparison; single and double layers samples were examined separately; EMSE, absorption and reflection properties analyzed and compared together.

\section{MATERIAL AND METHOD}

\subsection{Material}

\subsubsection{Composite yarn production}

In the study, metal composite yarns were produced by the commingling technique. The composite structure consisted of metal wire that centered two nylon filaments. Details of the production technique can be seen in Figure 1.
Copper $(\mathrm{Cu})$ wire with $50 \mu$ diameter was used as conductive components. The commingling process was conducted with 5 bar air pressure and $150 \mathrm{~m} / \mathrm{min}$ production speed. The technical features of raw materials are given in Table 1.

\subsubsection{Productions of knitted and woven fabrics}

1x1 rib knitted fabrics were produced using the copper composite yarns by Shima Seiki SFF152 flat knitting machine. Plain weave fabrics were produced with 22 ends/cm and 12 picks/cm densities by a projectile weaving machine. Copper composite yarns were used as weft and $150 \mathrm{den} / 36 \mathrm{f}$ textured polyester yarns were used as the warp in the woven structure. The previous studies noted that the EMSE of fabrics could be increased with an increase in the number of layers $[2,15,19]$. With a similar approach, two layers of knitted and woven fabrics were also produced by using the sewing technique. Besides, the two-layer copper plate was prepared for objective comparison. Surface images of samples with a 20x magnification ratio are given in Figure 2.

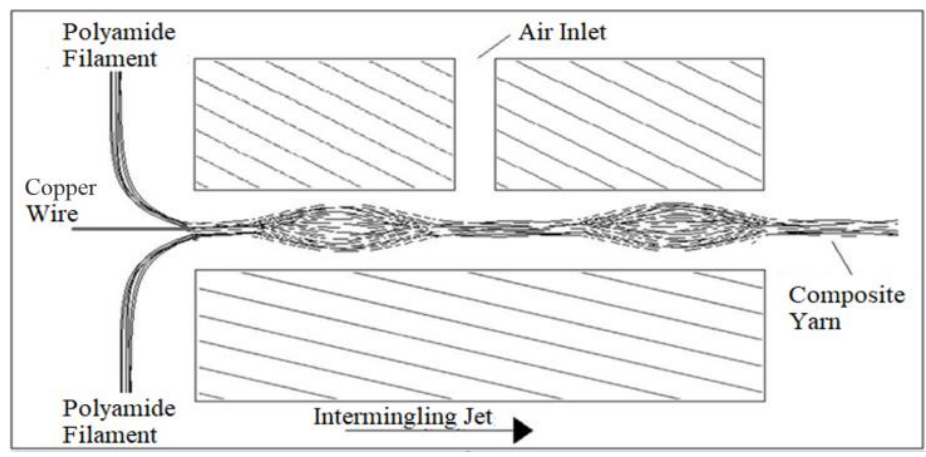

Figure 1. The composite yarn production process

Table 1. Technical features of raw materials

\begin{tabular}{ll}
\hline Filaments & Technical properties \\
\hline Polyamide 6.6 (PA) & 78 denier/ 68 filaments \\
Copper Monofilament $(\mathrm{Cu})$ & 157 denier $(50 \mu$ diameter $)$ \\
\hline Composite yarns & \\
\hline $\mathrm{PA}+\mathrm{Cu}+\mathrm{PA}$ & 306 denier/ 137 filaments \\
Copper Plate & $50 \mu$ thickness/ 300x600 $\mathrm{mm}$ \\
\hline
\end{tabular}
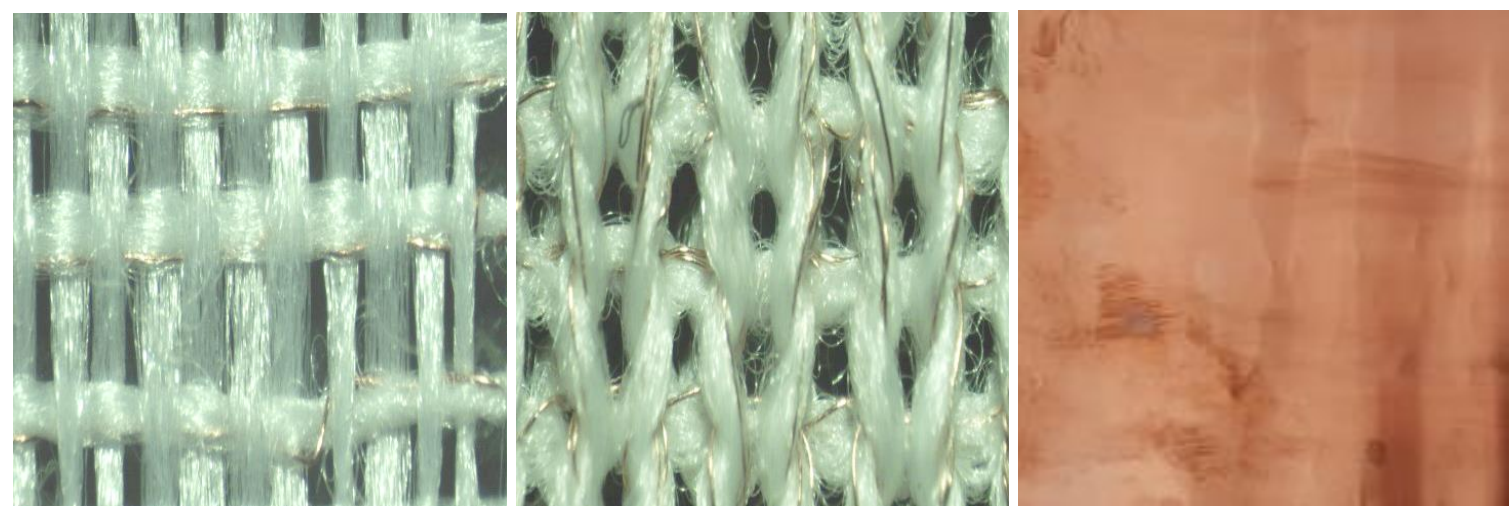

Figure 2. Copper composite (a) woven fabric, (b) knitted fabric and (c) copper plate 
Sample codes and descriptions with different properties were given in Table 2 .

\subsection{Method}

\subsubsection{Electromagnetic shielding effectiveness test}

The free space test method allows the measurement of the reflection (S11/S22) and transmission (S21/S12) coefficients in the usage environment of materials. Thus, this method was preferred for determining the electromagnetic characteristics of samples. Measurements were carried out between $0.8-5.2 \mathrm{GHz}$ frequency range by Agilent PNA-L model network analyzer. In the measuring process, single and double layer samples were placed between two horn antennas (Figure 3).

Table 2. Description of samples

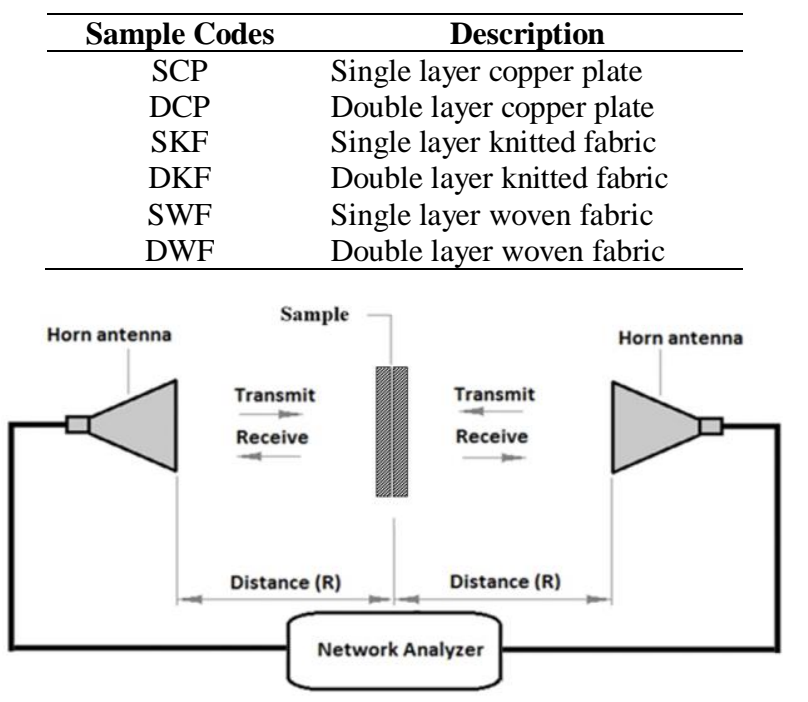

Figure 3. Measurement diagram

When the electromagnetic wave encounters a shield, it is attenuated by the reflection, absorption, and multiplereflection (generally neglected) components of EMSE. Shielding effectiveness is the sum of these three components. However, reflection and absorption are the major mechanisms in this phenomenon. The combined effect of reflection and absorption losses determines the effectiveness of the shield. The mentioned shielding mechanism can be seen in Figure 4 [1].

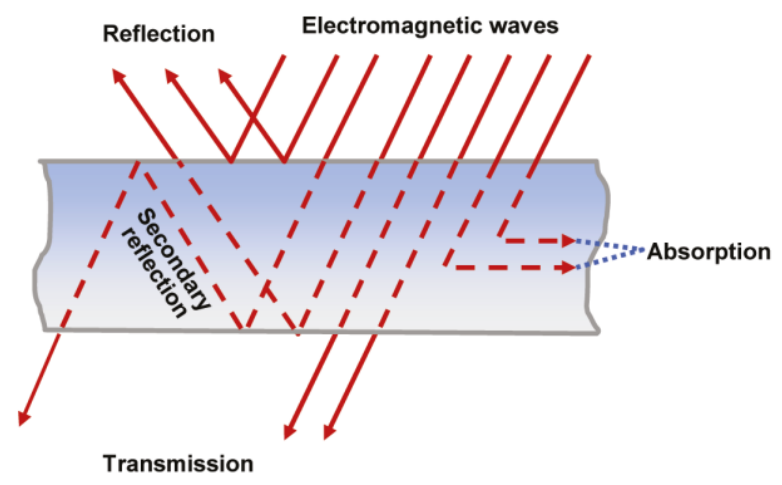

Figure 4. Electromagnetic shielding mechanism [1]
EMSE is the logarithmic form of the ratio between the electric field intensity, $(\mathrm{E})$ electric field intensity $(\mathrm{H})$, or power intensity $(\mathrm{P})$ with $\left(\mathrm{E}_{\mathrm{T}}, \mathrm{H}_{\mathrm{T}}, \mathrm{P}_{\mathrm{T}}\right)$ and without $\left(\mathrm{E}_{0}, \mathrm{H}_{0}\right.$, $\mathrm{P}_{0}$ ) shielding material. EMSE calculates as $\mathrm{dB}$ with the following Equation (1) [3, 20]:

$$
E M S E=20 \log \left|\frac{E_{0}}{E_{Y}}\right|=20 \log \left|\frac{H_{0}}{B_{T}}\right|=10 \log \left|\frac{P_{0}}{P_{T}}\right|
$$

Both reflection and absorption support the EMSE. However, secondary interference occurs with increasing reflection [21]. Özkan and Telli noted that the absorption and reflection components of shielding should be evaluated separately for better shielding characterization [2].

Reflectivity (R) and transmissivity (T) can be obtained experimentally and the absorptivity of samples can be expressed by using $\mathrm{R}$ and $\mathrm{T}$ as given in following Equations [22].

$$
\begin{aligned}
& R=\left|S_{11}\right|^{2}=\left|S_{22}\right|^{2} \\
& T=\left|S_{12}\right|^{2}=\left|S_{21}\right|^{2} \\
& A=1-(T+R)
\end{aligned}
$$

In the statistical analysis, measured scattering parameters of composite knitted/woven fabrics and copper plates were used for the calculations in the mentioned equations. The EMSE, reflection, and absorption components of shielding were analyzed and compared statistically. KolmogorovSmirnov test was applied for determining the normality of data. Test results showed that the distribution of data was not normal. Therefore, the Kruskal-Wallis and MannWhitney $U$ tests that are distribution-free and rank-based nonparametric methods were used for statistical comparisons [23, 24].

\section{RESULTS AND DISCUSSION}

In the study, the shielding performance of copper composite knitted and woven fabrics were compared with a copper plate having the same thickness with copper wire that used in fabric structures. All samples were prepared as both single and double layer. Shielding measurements were carried out in vertical and horizontal directions. EMSE, absorption, and reflection properties of samples were used for comparisons.

Measurements were conducted both vertical and horizontal directions of samples for determining the attenuation of electromagnetic waves that have different polarizations. EMSE of fabrics and copper plates were calculated using Equation 1. Measurements were performed at 1000 different frequency points. Woven fabrics were designed to contain metal only in the weft yarns (horizontal direction) since they can be easily produced in this way. In the weft knitted fabric structure, metal composite yarn shows 
continuity in the horizontal direction due to the nature of the production technique. Therefore, the EMSE values of knitted and woven fabrics generally were lower than $10 \mathrm{~dB}$ in horizontal directions. Only the copper plate samples provided electromagnetic shielding at a significant level against horizontally polarized waves (Figure 5). Thus, comparisons of metal plates and fabrics were made on the results in vertical directions. The measurement results were presented graphically in Figures 5 and 6.
Kruskal-Wallis and Mann-Whitney U test results of single layer samples for vertical direction are given in Table 3 .

There was a significant difference between the EMSE of copper plate and fabric samples for single and double layer types. The copper plate showed better performance than knitted and woven fabrics including copper wire. Maximum EMSE values are given in Table 4.

\subsection{EMSE and Absorption/Reflection Behaviors of Single and Double Layer Samples}
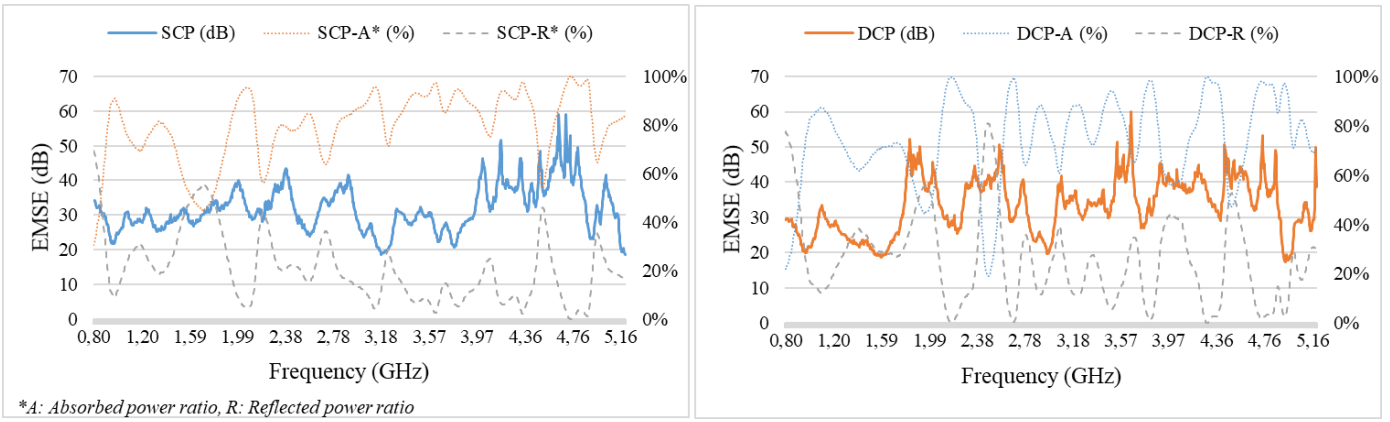

Figure 5. EMSE, absorption, and reflection results of copper plate in the horizontal direction

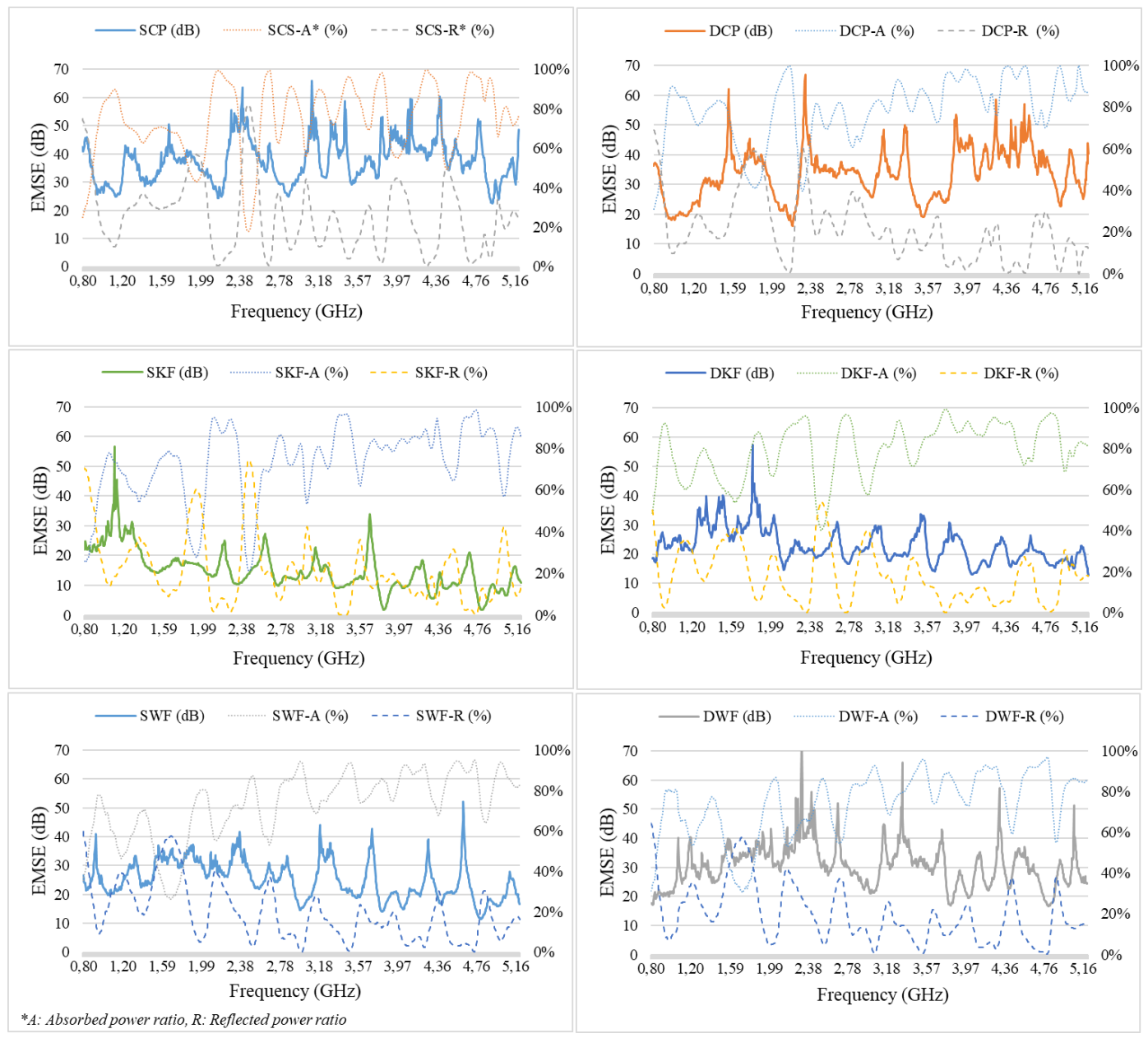

Figure 6. EMSE, absorption, and reflection results of samples in the vertical direction 
Table 3. Kruskal-Wallis and Mann-Whitney U tests results for single and layer samples

\begin{tabular}{llcccccc}
\hline \multirow{2}{*}{ Sample type } & \multicolumn{3}{c}{ Single layer } & \multicolumn{3}{c}{ Double layer } \\
\cline { 2 - 7 } & EMSE & Absorption & Reflection & EMSE & Absorption & Reflection \\
\hline \multirow{2}{*}{ Mean } & Copper Plate (CP) & $\mathbf{2 3 7 5 . 0 3}$ & 1547.89 & $\mathbf{1 6 6 6 . 0 6}$ & $\mathbf{1 9 6 0 . 2 6}$ & 1587.19 & $\mathbf{1 5 9 5 . 9 0}$ \\
Ranks & Knitted Fabric (KF) & $\mathbf{6 4 9 . 1 8}$ & 1490.20 & $\mathbf{1 4 7 3 . 1 2}$ & $\mathbf{8 5 1 . 2 5}$ & 1607.67 & $\mathbf{1 4 0 8 . 9 5}$ \\
& Woven Fabric (WF) & $\mathbf{1 4 7 7 . 2 9}$ & 1463.42 & $\mathbf{1 3 6 2 . 3 2}$ & $\mathbf{1 6 8 9 . 9 9}$ & $\mathbf{1 3 0 6 . 6 4}$ & $\mathbf{1 4 9 6 . 6 6}$ \\
\hline \multicolumn{2}{l}{ Asymp. Sig. } & 0.000 & 0.083 & 0.000 & 0.000 & 0.000 & 0.000 \\
\hline * Groups that marked in bold are statistically different from each other. \\
\hline
\end{tabular}

Table 4. Maximum EMSE values of samples

\begin{tabular}{lcrrc}
\hline & \multicolumn{4}{c}{ EMSE $(\mathrm{dB})$} \\
\hline \multirow{2}{*}{ Sample type } & \multicolumn{2}{c}{ Vertical direction } & \multicolumn{2}{c}{ Horizontal direction } \\
\cline { 2 - 5 } & Single layer & Double layer & Single layer & Double layer \\
\hline CP & $\mathbf{6 5 . 8 6}$ & $\mathbf{6 6 . 8 3}$ & $\mathbf{5 9 . 0 4}$ & $\mathbf{5 9 . 9 8}$ \\
KF & $\mathbf{5 6 . 6 6}$ & $\mathbf{5 7 . 1 2}$ & $\mathbf{1 1 . 0 9}$ & $\mathbf{9 . 3 4}$ \\
WF & $\mathbf{5 2 . 0 8}$ & $\mathbf{7 2 . 6 9}$ & $\mathbf{2 . 6 2}$ & $\mathbf{2 . 3 7}$ \\
\hline
\end{tabular}

In Table 4, although the copper plate showed EMSE both vertical and horizontal directions, knitted and woven fabrics provided significant electromagnetic protection only for the vertical direction. In previous studies, it was noted that the fabrics show better electromagnetic shielding in the direction containing metal wire $[2,11,16,17,25,26]$. Also, the increase in the number of layers increased metal content and thickness of shield and decreases the gaps in the structure. Thus, the increase in the number of layers increased the EMSE of samples at a statistically significant level for both directions. These results are consistent with the literature $[2,5,6,14,27]$. Mean rank values showed that the performance of the double layer fabrics was close to the copper plate for the vertical direction.

The reflection ratio of the copper plate was significantly higher than the knitted and woven fabrics for both single and double layer types. Moreover, woven fabrics have higher reflection values than knitted samples. Possible cause of this result that the copper wire follows a straight path in the woven structure than knitted fabrics. In previous studies, it was noted that the metal type has a significant effect on the absorbed and reflected power ratio of woven and knitted fabrics [2, 28]. Since all samples contain copper as metal content, their absorbed and reflected properties were similar to each other.

In the literature, it was emphasized that the EMSE of fabric samples decreases with an increase in frequency due to the smaller wavelengths of high frequency waves [2, 9, 29]. For this reason, copper plate and fabric samples were compared to determine the electromagnetic shielding behavior against increasing in wave frequency. Spearman correlation analyze was applied for determining the level and direction of the relation between EMSE and frequency. Correlation results are given in Table 5.

According to Table 5, EMSE of knitted and woven fabric samples showed a decreasing trend against increasing frequency. There was a moderate level negative correlation between EMSE and frequency. The correlation was weaker for double layer samples due to the increasing amount of metal content and the reduction of gaps in the structure. On the other hand, there was a positive weak correlation between frequency and EMSE of copper plates differently than the fabric samples. It can be said that the EMSE performance of copper plate increased against the increase of frequency. When Figures 5 and 6 examined together, EMSE of copper plate showed a more stable shielding trend than fabric samples against increasing frequency. The possible reason for this difference is that there is no gap in the surface of the metal plate as distinct from fabric samples. Similar correlation coefficients were obtained in the horizontal direction of the copper plate for EMSE (Single layer $=0.280$; Double layer $=0.378$ ). The copper plate exhibited similar EMSE values in different directions because of its isotopic structure. In a study about the metal composite fabrics, it was stated that these fabrics exhibited different electrical properties in different directions due to their anisotropic structure [30].

It was observed that the absorbed power ratio increased with the increase in the frequency for both copper plates and fabric samples. The possible cause of a similar tendency was the same metal content. Similar but the opposite trend was observed in the result of the reflected power ratio. The reflectance and absorption that are two important components of total shielding exhibited inverse changes as expected. The inverse trend between absorbed (Single layer: 0.299, Double layer: 0.490) and reflected power (Single layer: -0.298, Double layer: -0.486) ratio very close the each other for copper plate due to the isotropic structure of metal plate. The addition of a layer increased the absorbed power ratio against increasing frequency for all samples (Figure 5, 6 and Table 5). 
Table 5. Results of correlation analyze

\begin{tabular}{lcccccc}
\hline Layer type & \multicolumn{3}{c}{ Single layer } & \multicolumn{3}{c}{ Double layer } \\
\hline Sample code & CP & KF & WF & CP & KF & WF \\
\hline Correlation coefficient* & 0.202 & -0.693 & -0.473 & 0.321 & -0.541 & -0.150 \\
Sig. (2-tailed) & 0.000 & 0.000 & 0.000 & 0.000 & 0.000 & 0.000 \\
\hline *Frequency and EMSE & & & & & & \\
\hline & & & & & & 0.434 \\
\hline Correlation coefficient** & 0.299 & 0.526 & 0.703 & 0.490 & 0.599 \\
Sig. (2-tailed) & 0.000 & 0.000 & 0.000 & 0.000 & 0.000 & 0.000 \\
\hline **Frequency and absorbed power ratio & & & & & \\
\hline & -0.298 & -0.693 & -0.535 & -0.486 & -0.342 & -0.428 \\
\hline Correlation coefficient*** & 0.000 & 0.000 & 0.000 & 0.000 & 0.000 & 0.000 \\
Sig. (2-tailed) & \multicolumn{7}{c}{} \\
\hline ***Frequency and reflected power ratio & & & & & \\
\hline
\end{tabular}

\section{CONCLUSION}

In this study, electromagnetic protection performance of metal composite knitted and woven fabrics were compared with the copper plate in terms of EMSE, absorbed, and reflected power ratios. For this aim, copper wire with $50 \mu$ diameter was used in the fabric structure. A copper plate having $50 \mu$ thickness was preferred for objective comparison. EMSE tests were carried out with the Agilent PNA-L model network analyzer according to the free space test method between $0.8-5.2 \mathrm{GHz}$ frequency range. Tests were applied for vertical and horizontal directions of the samples (rotating 90 degrees clockwise) separately. The obtained results were analyzed statistically. The results were summarized below.

- Measurement results in vertical and horizontal directions showed that the copper plate has shielding ability against electromagnetic waves that come from various directions. However, woven and knitted fabrics can provide electromagnetic interference only in the direction of metal wire.

- According to EMSE results, copper plate showed better performance than fabric samples at a statistically significant level. However, the EMSE performance of double layer fabrics was close to the copper paper. Although EMSE increased with the increase in the number of layers, the shielding was not multi-axis for fabric samples. The copper plate exhibited similar

\section{REFERENCES}

1. Roh JS, Chi YS, Kang TJ, Nam, SW. 2008. Electromagnetic shielding effectiveness of multifunctional metal composite fabrics. Textile Research Journal 78(9), 825-835.

2. Özkan I, Telli A. 2019. The effects of metal type, number of layers, and hybrid yarn placement on the absorption and reflection properties in electromagnetic shielding of woven fabrics. Journal of Engineered Fibers and Fabrics 14, 1-13.

3. Brzeziński S, Rybicki T, Karbownik I, Malinowska G, Śledzińska K. 2012. Textile materials for electromagnetic field shielding made with the use of nano-and micro-technology. Open Physics 10(5), 11901196.
EMSE values in different directions due to the isotopic structure.

- Absorbed power ratios of copper plate and fabric samples were close the each other due to the same metal type in structures. On the other hand, the reflected power ratio of the copper plate was significantly higher than the knitted and woven fabrics. Moreover, woven fabrics have higher reflection values than knitted samples. Possible cause of this result that the copper wire follows a straight path in the woven structure than knitted fabrics.

- Correlation results between EMSE and frequency showed that the copper plate maintained its electromagnetic protection performance against increasing frequency. EMSE of copper plate showed more stable shielding behavior than fabric samples against increasing frequency. The possible reason for this difference is that there is no gap in the surface of the metal plate as distinct from fabric samples.

- As a conclusion, knitted and woven fabrics have the potential of electromagnetic shielding. However, different design alternatives should be studied for providing a stable and multi-axial electromagnetic shielding at the metal plate level. The results of this study reveal that the gaps in the fabric structure, the number of fabric layers, and the orientation of the metals in the structure are important factors to reach shielding at the level of the metal plate.

4. Su CI, Chern JT. 2004. Effect of stainless steel-containing fabrics on electromagnetic shielding effectiveness. Textile Research Journal 74(1), 51-54.

5. Cheng KB, Cheng TW, Nadaraj RN, Dev VG, Neelakandan NR. 2006. Electromagnetic shielding effectiveness of the twill copper woven fabrics. Journal of Reinforced Plastics and Composites 25(7), 699-709.

6. Perumalraj R, Dasaradan BS, Anbarasu R, Arokiaraj P, Harish SL. 2009. Electromagnetic shielding effectiveness of copper core-woven fabrics. The Journal of The Textile Institute 100(6), 512-524. 
7. Ortlek HG, Kilic G, Okyay G, Bilgin S. 2011. Electromagnetic shielding characteristics of different fabrics knitted from yarns containing stainless steel wire. Industria Textila 62(6), 304-308.

8. Rajendrakumar K, Thilagavathi G. 2012. Electromagnetic shielding effectiveness of copper/PET composite yarn fabrics. Indian Journal of Fiber and Textile Research 37(2), 133-137.

9. Duran D, Kadoğlu H. 2012. Research on electromagnetic shielding with copper core yarns, Tekstil ve Konfeksiyon 22(4), 354-359.

10. Duran D, Kadoğlu H. 2015. Electromagnetic shielding characterization of conductive woven fabrics produced with silvercontaining yarns, Textile Research Journal 85(10), 1009-1021.

11. Ortlek HG, Alpyildiz T, Kilic G. 2013. Determination of electromagnetic shielding performance of hybrid yarn knitted fabrics with anechoic chamber method. Textile Research Journal 83(1), 90-99.

12. Hwang PW, Chen AP, Lou CW, Lin JH. 2014. Electromagnetic shielding effectiveness and functions of stainless steel/bamboo charcoal conductive fabrics. Journal of Industrial Textiles 44(3), 477 494.

13. Yu ZC, Zhang JF, Lou CW, He HL, Chen AP, Lin JH. 2015 Determination of electromagnetic shielding and antibacterial properties of multifunctional warp-knitted fabrics. The Journal of The Textile Institute 106(11), 1203-1211.

14. Lin JH, Jhang JC, Lin TA, Huang SY, Chen YS, Lou CW. 2017 Manufacturing techniques, mechanical properties, far infrared emissivity, and electromagnetic shielding effectiveness of stainless steel/polyester/bamboo charcoal knits. Fibers and Polymers 18(3), 597-604.

15. Jagatheesan K, Ramasamy A, Das A, Basu A. 2018. Electromagnetic shielding effectiveness of carbon/stainless steel/polypropylene hybrid yarn-based knitted fabrics and their composites. The journal of the Textile Institute 109(11), 1445-1457.

16. Volski V, Vandenbosch GA. 2009. Full-wave electromagnetic modelling of fabrics and composites. Composites Science and Technology 69(2), 161-168.

17. Priniotakis G, Sfyroera E, Symeonidis S, Mitilineos SA, Vassiliadis S Zafeiri C, Moudatsou S. 2018. Effects of different conductive yarns' knitting structure on electromagnetic shielding effectiveness. IOP Conference Series: Materials Science and Engineering, 459(1), 1-6.

18. Özkan İ, Duru Baykal P, Karaaslan M. 2020. Investigation of electromagnetic shielding properties of metal composite tufted carpets. The Journal of The Textile Institute, 111(4), 476-483.
19. Chen HC, Lee KC, Lin JH, Koch M. 2007. Fabrication of conductive woven fabric and analysis of electromagnetic shielding via measurement and empirical equation. Journal of Materials Processing Technology, 184(1-3), 124-130.

20. Liang R, Cheng W, Xiao H, Shi M, Tang Z, Wang N. 2018. A calculating method for the electromagnetic shielding effectiveness of metal fiber blended fabric. Textile Research Journal 88(9), 973-986.

21. Tong H, Zhu G, Mao W. 2011. Development of EMI shielding materials characterized by low secondary electromagnetic radiation pollution. Second International Conference on Mechanic Automation and Control Engineering, 2075-2077.

22. Jiang W, Yan L, Ma H, Fan Y, Wang J, Feng M, Qu S. 2018. Electromagnetic wave absorption and compressive behavior of a three-dimensional metamaterial absorber based on 3D printed honeycomb. Scientific Reports, 8(1), 4817.

23. Hollander M, Wolfe D, Chicken E. 2013. Nonparametric Statistical Methods. Hoboken, NJ: John Wiley \& Sons.

24. Sheskin DJ. 2003. Handbook of Parametric and Nonparametric Statistical Procedures. New York: CRC Press.

25. Ceken F, Kayacan Ö, Özkurt A, Uğurlu SS. 2012. The electromagnetic shielding properties of some conductive knitted fabrics produced on single or double needle bed of a flat knitting machine. Journal of the Textile Institute 103(9), 968-979.

26. Mühl T, Obelenski B. 2004. Knitted and warp-knitted fabrics offering electromagnetic shielding, Melliand Textilberichte, 85, 7-8

27. Lou CW, Lin TA, Chen AP, Lin JH. 2016. Stainless steel/polyester woven fabrics and copper/polyester woven fabrics: Manufacturing techniques and electromagnetic shielding effectiveness. Journal of Industrial Textiles 46(1), 214-236.

28. Özkan İ. 2020. Investigation of the technical and physical properties of metal composite $1 \times 1$ rib knitted fabrics. Industria Textila 71(1), 4149

29. Asghar A, Ahmad MR, Yahya MF, Ali MT, Ab Aziz AA, Abd Rahman NH, Zameer Ul Hassan S, Kashif, M. 2018. An alternative approach to design conductive hybrid cover yarns for efficient electromagnetic shielding fabrics. Journal of Industrial Textiles 48(1), 38-57.

30. Tokarska M, Orpel M. 2019. Study of anisotropic electrical resistance of knitted fabrics. Textile Research Journal 89(6), 1073-1083. 